\title{
Patrimonio arquitectónico industrial: Una oportunidad para la reconversión y revitalización en la ciudad
}

\author{
Industrial architectural heritage: An opportunity for redevelopment and revitalization \\ in the city
}

$<$ Resumen>

El presente artículo muestra la importancia del patrimonio Industrial en la construcción de la memoria cultural y social de las ciudades de nuestro país que vivieron el proceso de modernización propio de las últimas décadas del siglo xix y principios del siglo xx. Tal patrimonio no sólo permite construir los antecedentes del pasado, sino también, revalorizar estas estructuras a partir de la actualización de su uso.

$<$ Abstract $>$

This article presents the importance of industrial heritage in the construction of the social and cultural memory of the cities in our country, cities which lived through the modernization process of the last decades of the nineteenth century and early twentieth century. Heritage that not only allows to build the background of the past, but can also be revalued through an actualization of its use.

<PALABRAS CLAVE >

PATRIMONIO ARQUITECTÓNICO INDUSTRIAL / MEMORIA CULTURAL / RECONVERSIÓN

<KEYWORDS>

INDUSTRIAL ARCHITECTURAL HERITAGE / CULTURAL MEMORY \& RECONERSION
La necesidad de valorar el Patrimonio Arquitectónico Industrial

La idea de proteger el Patrimonio Arquitectónico Industrial es de reciente data en el concierto internacional y por supuesto local. Si pensamos en ello, podemos señalar que la primera indicación y reconocimiento mundial de la necesidad de preservar el patrimonio arquitectónico ocurre con la Carta de Atenas de 1931; sin embargo habrá que esperar hasta 1972 en que la UNESCO elabore la Convención para la Protección del Patrimonio Mundial, Cultural y Natural ${ }^{1}$, una declaración que no incluirá expresamente al Patrimonio Arquitectónico Industrial, pero que ha permitido proteger algunos casos relevantes dentro de esta tipología, como lo fueron las Minas de Sal de Wieliczka en Polonia inscritas en 1978, siendo éste el primer caso de Patrimonio Arquitectónico Industrial reconocido mundialmente.

El documento más importante y específico sobre la necesidad de valorar y proteger este patrimonio lo constituye la Carta de Nizhny

\footnotetext{
Académica del Departamento de Historia y Teoría de la Arquitectura de la Facultad de Arquitectura de la Universidad de Chile, además coordina el Archivo de Arquitectura Chilena. Realiza actualmente los cursos de Historia de la Arquitectura Chilena y Americana y Teoría de la Arquitectura y ha investigado sobre patrimonio arquitectónico nacional, realizando diversas publicaciones. Se encuentra realizando su tesis de Doctorado, para el programa de Doctorado en Arquitectura y Urbanismo de la Universidad Politécnica de Madrid.

** Directora del Departamento de Historia y Teoría de la Arquitectura de la Facultad de Arquitectura de la Universidad de Chile, además Coordina la Unidad de Relaciones Internacionales de la Facultad. Posee un Magíster en Arquitectura de la Washington University (1980). Realiza actualmente el curso de Teoría de la Arquitectura y ha investigado sobre arquitectura en madera y patrimonio arquitectónico nacional, realizando diversas publicaciones. Se encuentra realizando su tesis de Doctorado, para el programa de Doctorado en Arquitectura y Urbanismo de la Universidad Politécnica de Madrid.

En: www.patrimonio-mundial.com/unescol.htm
} 
Patrimonio Mundial de UNESCO,

Campamento Minero de Sewell.
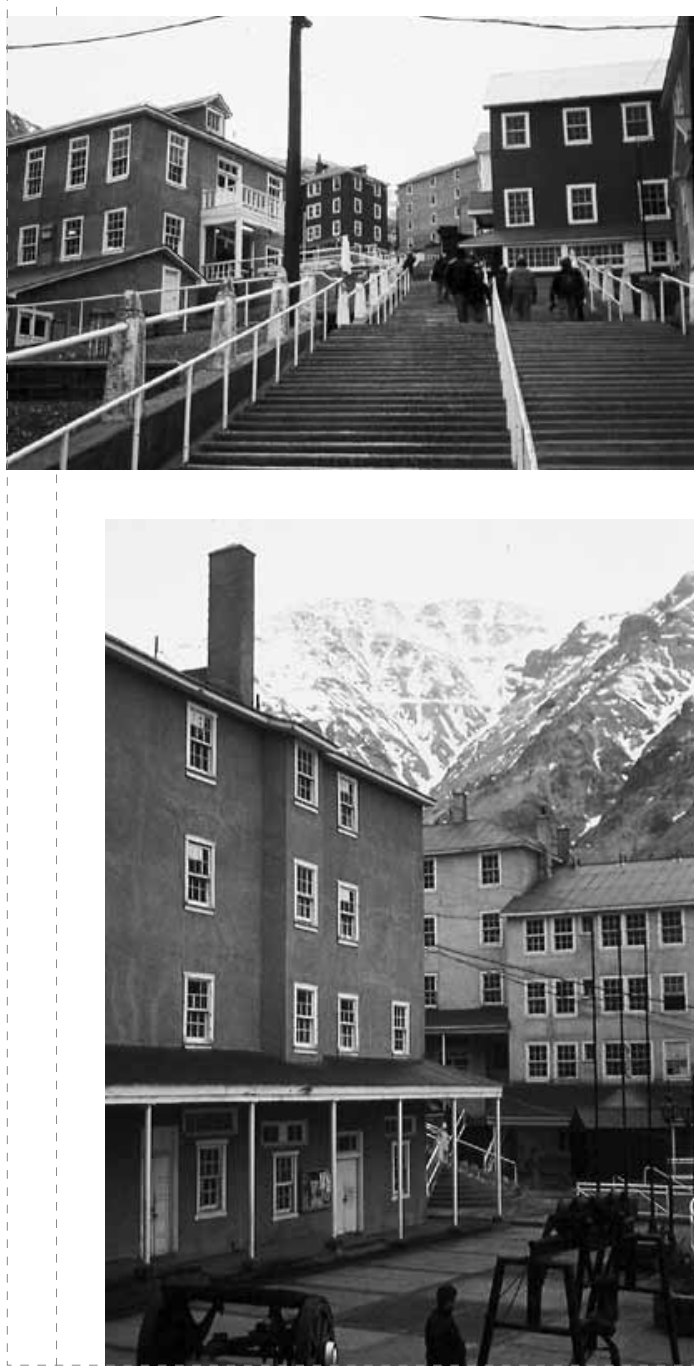

Tagil firmada en el año 2003 en Moscú a instancias de $\mathrm{TICCIH}^{2}$, organización mundial consejera de ICOMOS (UNESCO) en lo referido particularmente al Patrimonio Arquitectónico Industrial.

Cabe señalar que en nuestro país el instrumento que protege el patrimonio arquitectónico y cultural es la Ley No 17.288 de Monumentos Nacionales (1970), cuerpo legal que no reconoce expresamente la existencia de un patrimonio diverso y particular como lo es el industrial, pero que sin embargo se ha permitido proteger algunas estructuras de este orden y que a través de la gestión del Consejo de Monumentos Nacionales y organizaciones privadas, ha logrado incorporar a la lista del Patrimonio Mundial de UNESCO el caso de las salitreras de Humberstone y Santa Laura $^{3}$ en el norte o el Campamento Minero de Sewell ${ }^{4}$.

Así no es de extrañar que las grandes, y a veces toscas, instalaciones industriales en desuso sean demolidas y reemplazadas por nuevas estructuras, puesto que no existe aún la conciencia generalizada de que ellas son el ejemplo vivo de un momento histórico de la modernidad, como lo fue la industrialización. Un proceso que ocurrió con distinta intensidad y evolución en los diversos países del orbe y que por ello constituye una ineludible muestra de la propia memoria histórica y cultural, superando con ello la tradicional visión que valora sólo el origen histórico de las antiguas construcciones.

En tal sentido el Patrimonio Arquitectónico Industrial constituye una muestra clara del valor cultural y social de los procesos productivos que marcaron la era industrial en cada lugar, dando cuenta de una propia historia económica, social y cultural; complejos que hoy se encuentran abandonados 0 superados y que por ello creemos deben ser preservados, no sólo como edificios posibles de recorrer o visitar aprendiendo de los procesos productivos que albergaron, sino como elementos vivos dentro de la ciudad adoptando y aportando nuevos usos y funciones, demostrando con ello la versatilidad y capacidad de estas estructuras creadas inicialmente, sólo para albergar máquinas y procesos industriales.

\section{Patrimonio Arquitectónico Industrial en Santiago}

El desarrollo de la industria en Santiago de Chile se produce a fines del siglo xix $y$ principios del $x x$

Poco antes de terminar el siglo xIx se dictan leyes para fomentar la industria nacional, de igual modo la Primera Guerra Mundial se traduce en un nuevo impulso para la industria al iniciarse la fabricación de diversos artículos que por dificultades de transporte no podían importarse. Sin embargo luego de superado el conflicto bélico, la mayor parte de las industrias debieron reducir o paralizar sus faenas a razón de la competencia con productos importados. También a fines del siglo xIx se produce el auge del salitre para luego en la primera década del siglo xx asumir el impulso de la explotación del cobre; así llegan al país capitales norteamericanos y franceses con dicho fin, iniciándose la explotación de diversas instalaciones mineras.

Junto con ello se inicia una época de política económica proteccionista y empieza en 1904 una fiebre de negocios industriales, se declaran libres de derechos de internación los útiles y materiales para la instalación de la industria siderúrgica en el país y se promueven las importaciones de máquinas lo que reducirá posteriormente a raíz de la Primera Guerra Mundial.

En 1916 se dictan las primeras leyes sociales asociadas al proceso industrial, como la de Accidentes del Trabajo, en 1917 la de Salas Cunas y luego la que establece el descanso dominical, que promoverán y garantizarán un adecuado desarrollo industrial a nuestro país y sus trabajadores.

Así en 1928 se realiza en el país el primer censo industrial siendo de 8.467 el número de establecimientos; de ellos sólo la cuarta parte ocupaban más de cinco personas, lo que indica el carácter artesanal que conservaba hasta entonces la industria nacional.

Desgraciadamente la crisis internacional del año 1929, dejó en evidencia la fragilidad de la economía chilena, la capacidad importadora cayó bruscamente y la actividad exportadora debió paralizar sus faenas, produciendo una fuerte cesantía, lo que obligó a desarrollar la industria interna para superar la crisis.

Es así como a partir de 1932 se controlan las divisas y se incorpora un importante número de obreros de las faenas mineras paralizadas a las diversas actividades industriales, se aprovecha al máximo la capacidad instalada de la industria manufacturera, se mejoran las técnicas de producción y se crean numerosos talleres. Con ello los diferentes gobiernos realizan esfuerzos para desarrollar la industria, lo que se manifiesta de manera importante en la creación en 1939 de la Corporación de Fomento de la Producción, CORFO, durante el gobierno de Pedro Aguirre Cerda.

Por su parte la Segunda Guerra Mundial da un impulso temporal a la industrialización, sin embargo el establecimiento de la Industria Siderúrgica de Huachipato en 1950 y la Refinería de Con Con en 1954 y la continuación de la electrificación del país a cargo de Endesa, crean finalmente las condiciones favorables para una nueva
The International Committee for the Conservation of the Industrial Heritage.
Lista del Centro del Patrimonio Mundial de la UNESCO, 2005.

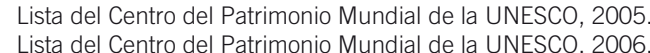


expansión industrial. En tal sentido es interesante citar a Aurelio Montenegro en un estudio sobre la industria fabril en Chile ${ }^{5}$ quien comentaba: «Chile, como pocos países en el mundo, puede enorgullecerse de tener una riqueza minera tan variada, un mar tan extenso y un suelo tan fértil para que florezcan las más necesarias industrias. Su naturaleza ofrece recursos que se aprovechan en forma limitada todavía. Esto nos lleva al convencimiento que el porvenir de Chile, está en la industria fabril y manufacturera».

De esta manera se consolida el desarrollo industrial en nuestro país, particularmente en Santiago, donde el emplazamiento de las industrias estuvo mayoritariamente asociado a un ferrocarril que se fue construyendo en la medida que surgían las necesidades de abastecimiento de materias primas y distribución de productos, tanto para esta ciudad capital como para el resto del país.

Con ello se generó un «anillo de hierro» en torno a la ciudad, en cuyos bordes comenzaron a surgir importantes estructuras fabriles, industrias que alcanzaron un alto número, quedando hoy muy pocas de ellas. Estas instalaciones fueron reconocidas en una investigación FONDECYT realizada por las autoras durante los años 2005 y 2006 , durante esta investigación se pudo detectar más de ochenta casos en pie, siendo muy pocos los que mantenían su uso original, estando la mayoría en condición de abandono o reconvertidos en bodegas, denotando la fragilidad de su posible salvaguarda.

Estas instalaciones con el paso del tiempo, la llegada de nuevas tecnologías y el propio crecimiento de la ciudad, quedaron obsoletas, produciendo hoy una cicatriz urbana en los terrenos del llamado Anillo de Hierro, que coincide con los límites de la actual comuna de Santiago, todos ellos terrenos valiosos e insertos en un área urbana de grandes posibilidades.

Es por ello que dentro de la serie de proyectos emblemáticos generados con motivo del Bicentenario de la Independencia de nuestro país por el Gobierno, se ha propuesto la recuperación de estas áreas -en donde se sitúan estos conjuntos industriales- con el fin de gatillar proyectos estratégicos que permitan la revitalización de estos sectores, proyectos que a veces desconocen el valor de estas estructuras, con el inminente peligro de su desaparición.

Aurelio Montenegro. Estudio General de la Industria Fabril de Chile. 1947.

\section{Casos emblemáticos recuperados}

Sin embargo, hay acciones privadas que han permitido recuperar estas estructuras para reconvertirlas, basándose muchas veces en sus grandes instalaciones, excelente ubicación y las potencialidades de una arquitectura que por racional da cabida a diversas funciones. Ellos son los casos que quisiéramos destacar con el fin, no sólo de poner en valor, sino de presentar y reconocer las posibilidades de este singular patrimonio arquitectónico que nos permite perpetuar en la memoria los orígenes de nuestra sociedad industrializada.

En tal sentido presentamos un conjunto de casos relevantes en torno al anillo que han sido reconocidos, protegidos y reciclados; entre los que destacan el ex Galpón de la Dirección de Aprovisionamiento de Ejército, DAE, hoy Centro Cultural Matucana 100; la ex Maestranza de Tranvías; hoy destinada a Feria de Antigüedades y misceláneos en la Avenida Balmaceda; la ex Fábrica de Gas de San Borja que mantiene parcialmente su destino original; el ex Molino Bellavista convertido en espacio público; los galpones de Chucre Manzur que hoy acogen teatros y otras expresiones culturales; la ex fábrica Nacional de Vidrios reconvertida en estudios de Televisión (Megavisión); la ex Fábrica Nacional de Catres hoy oficinas centrales de ONEMI en calle Beaucheff; la ex Central de Leche en el barrio de la maestranza San Eugenio, hoy convertida en establecimiento educacional; la ex fábrica de sombreros Girardi que acoge un importante centro gastronómico en Avenida Italia y la antigua Manufactura Chilena de Algodón Yarur S.A (MACHASA), en proceso de reconversión para acoger los estudios de Chilevisión.

Dentro de ellas nos detendremos en tres casos, que por su magnitud y relevancia en el ámbito urbano nos parecen los de mayor provocación, ellos son la ex Fábrica Nacional de Vidrios; la ex Central de Leche y la antigua Manufactura Chilena de Algodón Yarur S.A (MACHASA)

El primero de ellos remonta en su construcción a la década de 1930 cuando se instalara en la Avenida Vicuña Mackenna N 1.348 para reemplazar las antiguas instalaciones que ocupaban en el sector de la metro estación Franklin. El edificio empleó la más avanzada tecnología constructiva y fabril para producir vidrios quedando obsoleta en la década de 1970 cuando se traslada a sus actuales instalaciones (1975). En los años noventa el empresario Ricardo Claro, recientemente fallecido, decide instalar en este edificio los estudios de Televisión de un nuevo canal, Megavisión, situación que no sólo ha permitido revitalizar el edificio reciclándolo, sino que ha dado vida a un sector marcado por la presencia de instalaciones industriales mayores, que aprovechaban los fondos de sus predios para establecer relación con el ferrocarril, pero que significaban un límite claro para la continuidad de la trama urbana hacia el oriente, sumado ello al hecho de conformar un borde duro e impenetrable a la actividad peatonal.

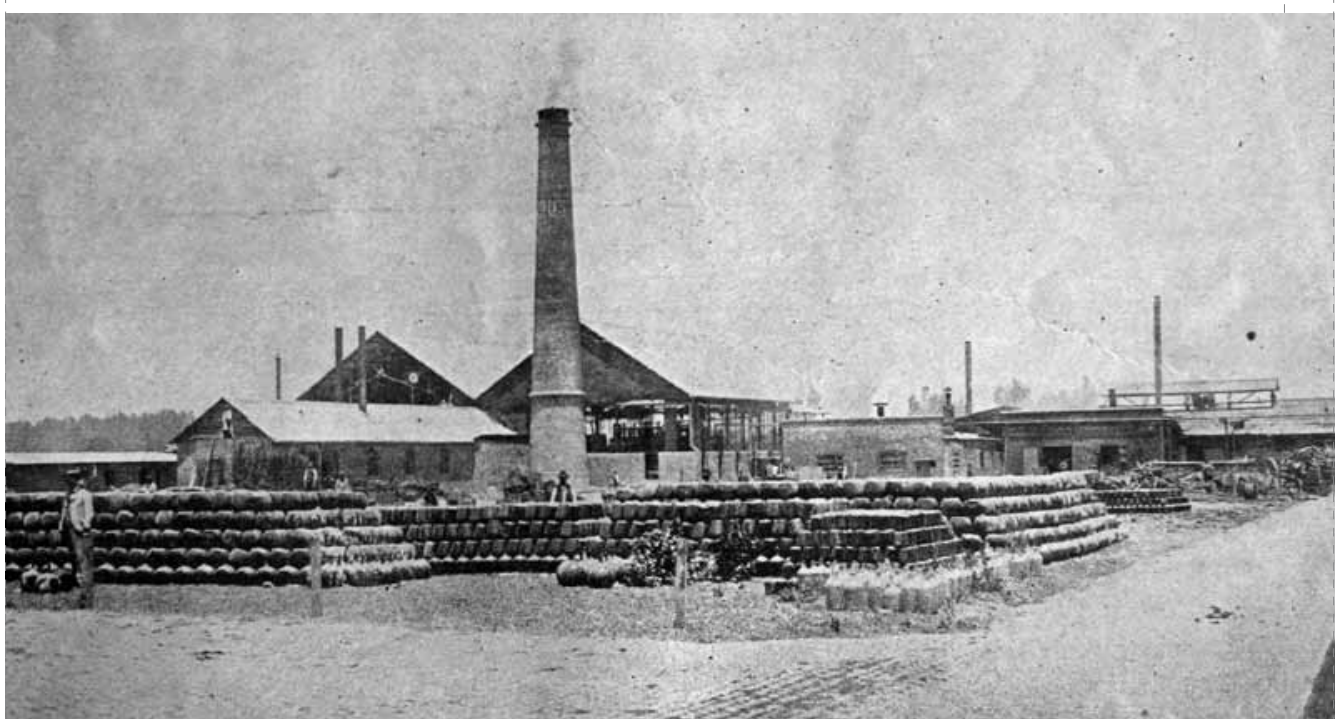


Actualmente en la Ex Fábrica Nacional de Vidrios funcionan los estudios de televisión del canal Megavisión, situación que no sólo ha permitido revitalizar el edificio reciclándolo, sino que ha dado vida a un sector marcado por la presencia de instalaciones industriales mayores.
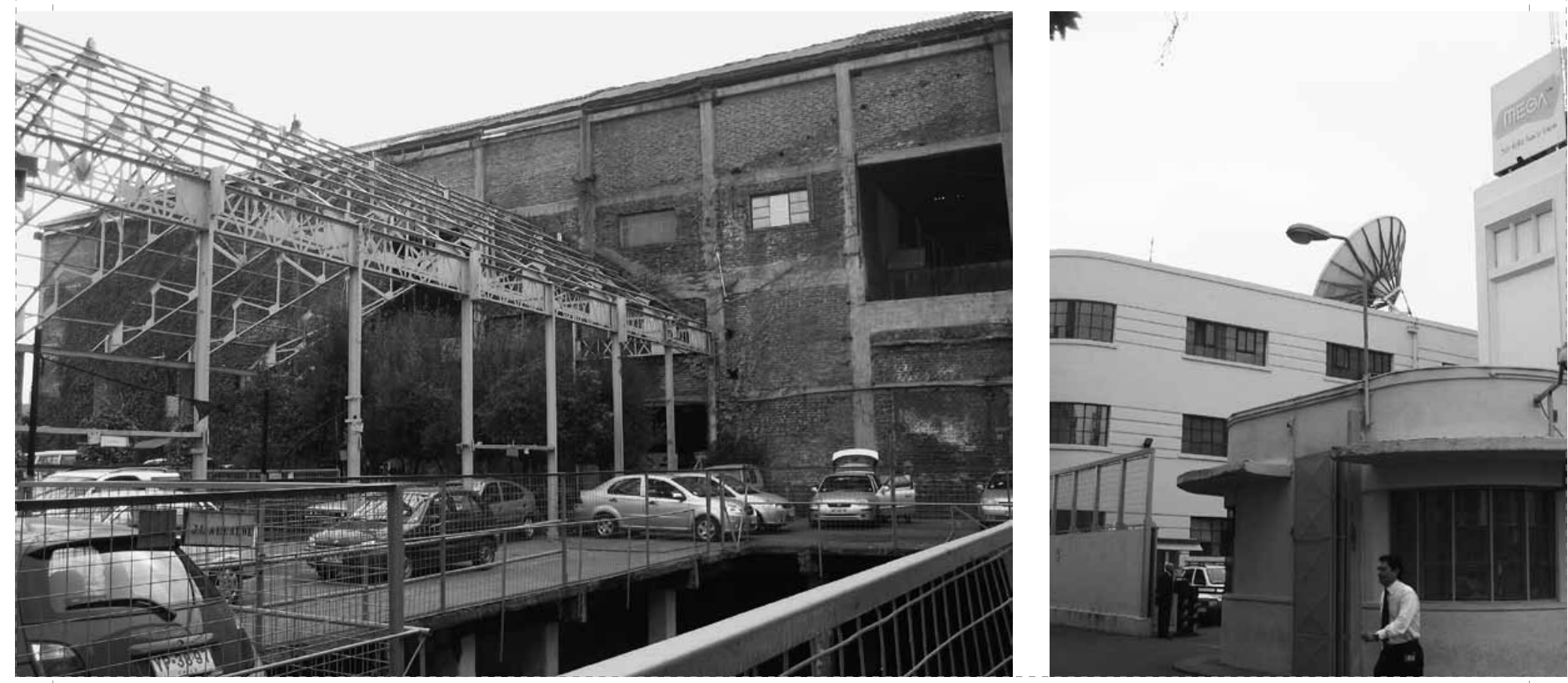

Un segundo caso lo constituye la ex Central de Leche, el que nos parece relevante, tanto por su magnitud como imagen arquitectónica, destacando dentro del sector por su lenguaje protorracionalista sumado a su capacidad de albergar nuevos usos, como lo es el de educación que sirve en la actualidad.

El edificio también se construyó en hormigón armado y con un lenguaje próximo al Art Deco, este conjunto data de la década de 1930. Ocupa una manzana completa en torno a la que aún persisten los antiguos tendidos del ferrocarril que permitían el movimiento de su producción. Este complejo industrial cuenta además con un conjunto de viviendas obreras en un predio vecino, el que sumado a la población de ferrocarriles próxima y referida a la Maestranza de San Eugenio consolida aún más el carácter industrial de sector, situación que lo hace merecedor de políticas de protección urbana y de paisaje cultural, las que desgraciadamente aún no han sido implementadas, quizá por la falta de valoración de este singular patrimonio arquitectónico.

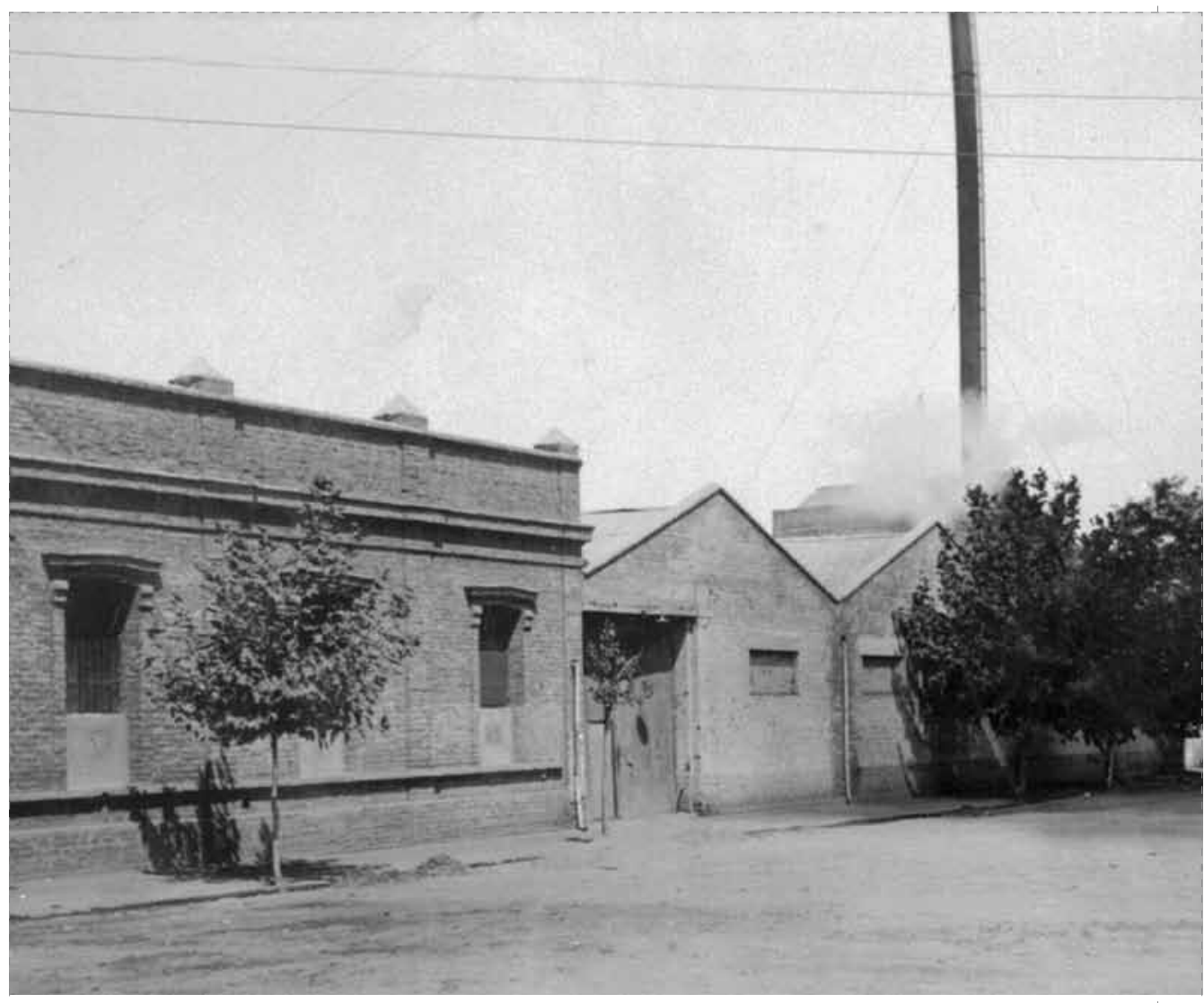

Ex Central de Leche, ocupaba una manzana completa en torno al antiguo ferrocarril que permitía el movimiento de su producción. 
Actualmente en la Ex Central de Leche funciona el Liceo Industrial de la Construcción
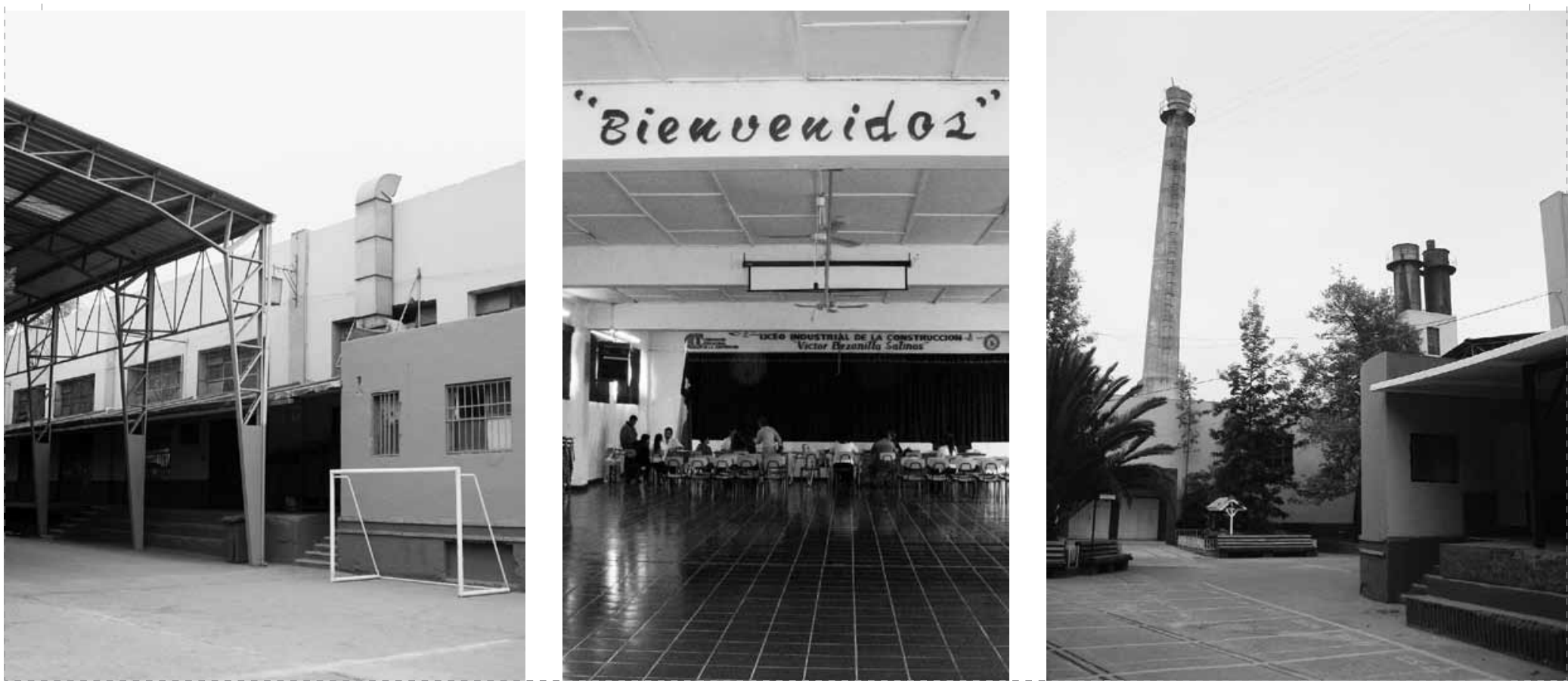

Finalmente quisiéramos destacar el conjunto de la antigua Manufactura Chilena de Algodón Yarur S.A. (MACHASA), el que sobresale como un interesante ejemplo de arquitectura industrial que además incorporó el concepto de la vivienda obrera en su planeamiento general. Las instalaciones industriales superan los veinticinco mil metros cuadrados de superficie habitable y fueron construidas entre los años 1936 y 1938 por el arquitecto Alberto Cruz Eyzaguirre ${ }^{6}$ utilizando las técnicas constructivas y arquitectónicas de mayor avance, lo que permitió generar un complejo reconocido, no sólo por su magnitud, sino por su calidad arquitectónica. El conjunto se emplaza en el borde sur de la Comuna de Santiago, aprovechando la conectividad del predio producto del vigente ferrocarril de circunvalación, el que le proveía de los insumos necesarios para la fabricación de telas, al igual que la posibilidad de carga para su distribución. Se componía no sólo de la fábrica, sino que incluía viviendas para obreros, un estadio, colegio y sala cuna para los hijos de los trabajadores en el barrio, al igual que bodegas en un predio anexo, las que se conectan por un túnel bajo la calle.

6 Seminario de Investigación, Facultad de Arquitectura y Urbanismo, Universidad de Chile. Patrimonio arquitectónico industrial del siglo xx: Manufactura Chilenas de Algodón Yarur S.A. Alumno: Viviana Macho Chávez. Profesor guía: María Paz Valenzuela y Juan Benavides, 2000

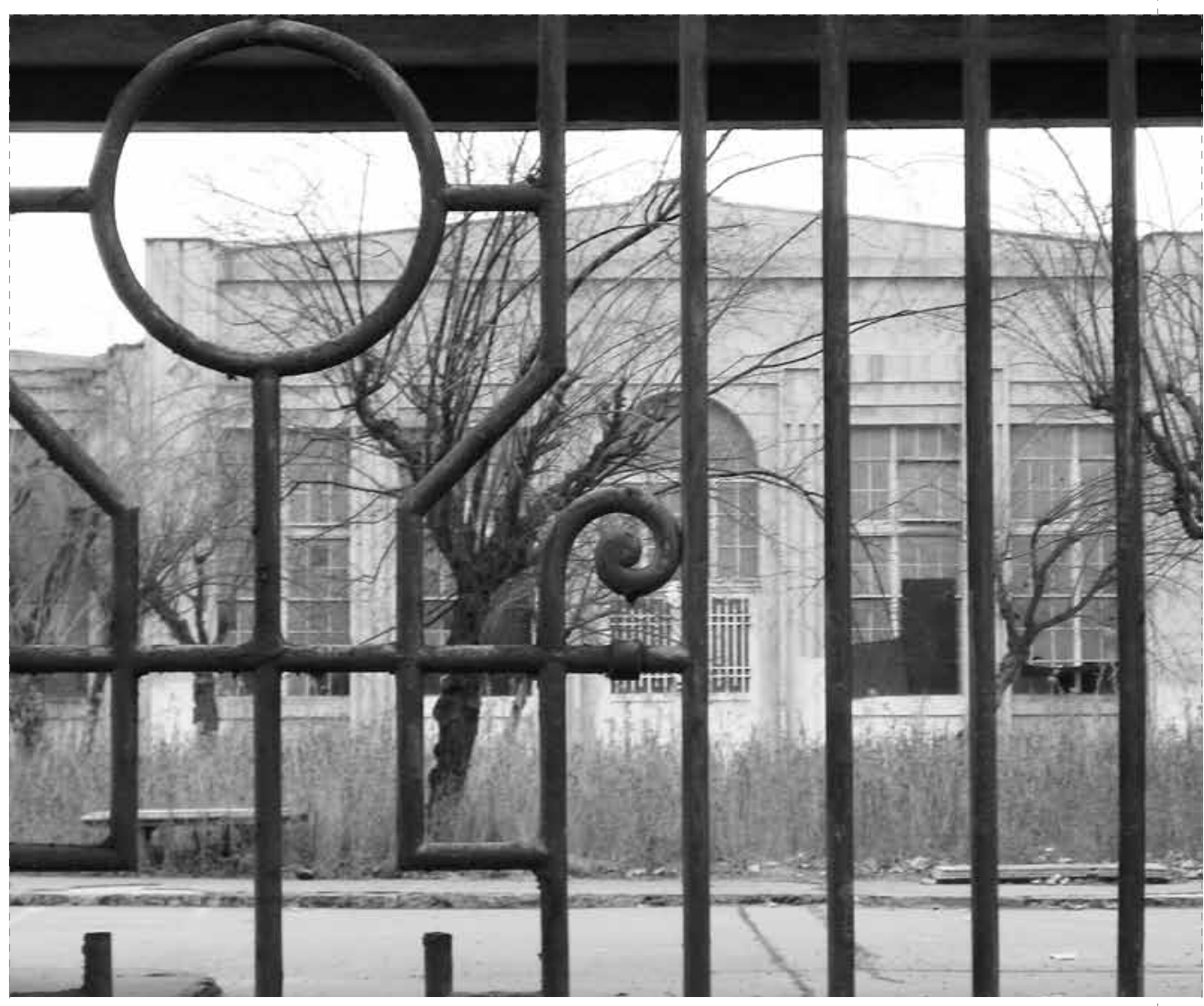

Ex Manufactura Chilena de Algodón Yarur S.A (MACHASA), un ejemplo de arquitectura industrial que incorporaba el concepto de la vivienda obrera en su planeamiento general. 


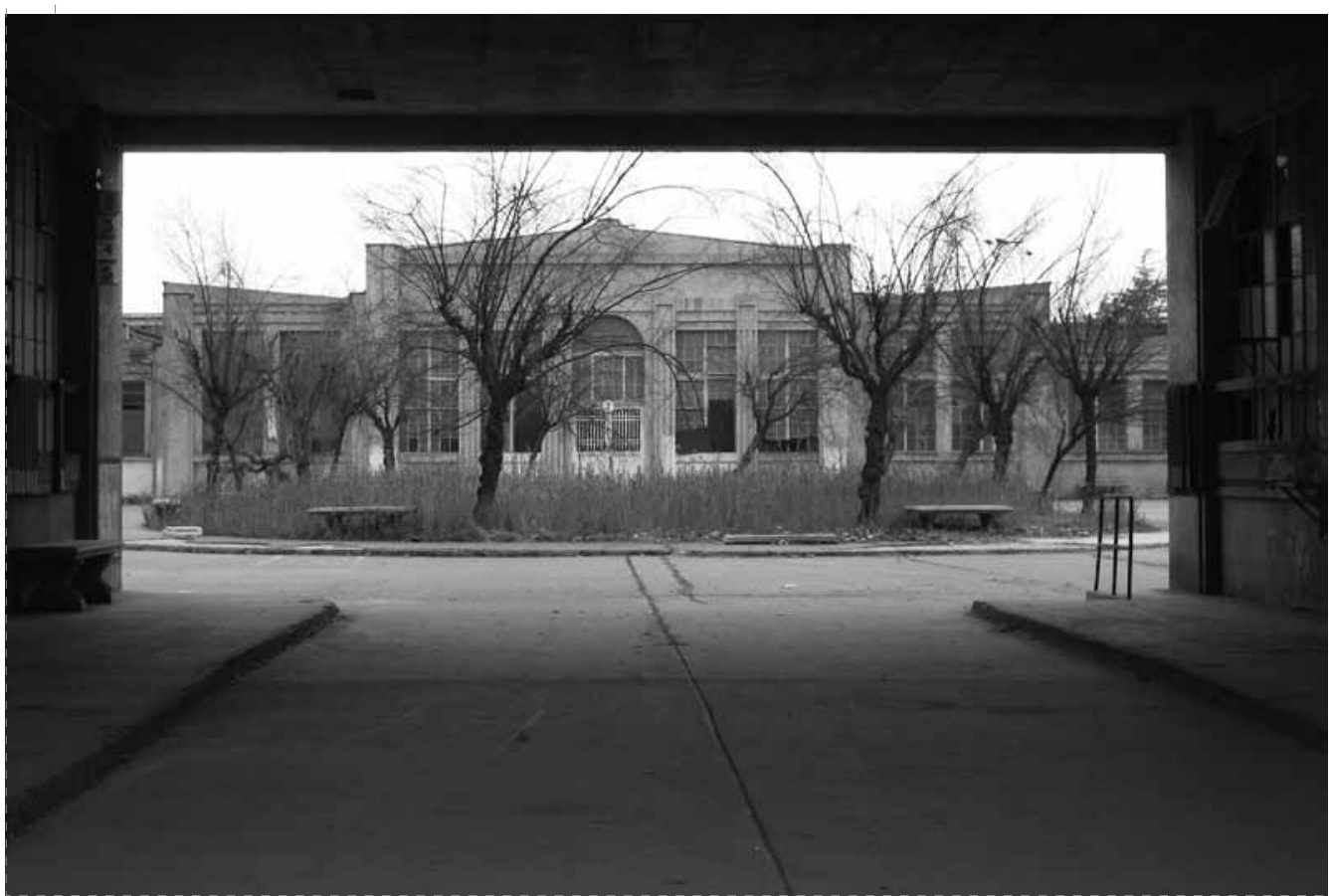

La fábrica textil funcionará en estas dependencias hasta 1983 en que se produce la quiebra de la empresa y venta de sus activos, para un posterior remate del inmueble lo que lo tuvo abandonado por muchos años y en peligro de desaparecer, sin embargo hoy se encuentra en proceso de rehabilitación para albergar estudios de televisión, dando con ello una muestra clara de la capacidad y versatilidad de estos complejos arquitectónicos que superan lo puramente industrial.

\section{Conclusiones}

Si bien hemos detectado un número importante de casos de patrimonio arquitectónico industrial asociado al FCS, ellos están en serio peligro de desaparecer.

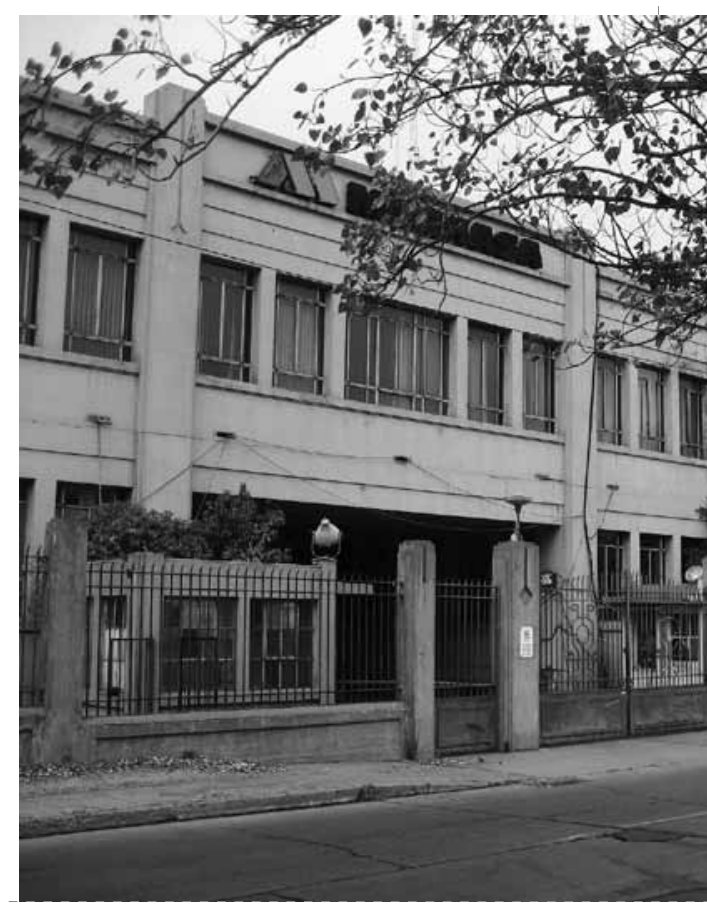

Instancias de crecimiento y mejoramiento urbano los ignoran, tal como ocurrió en la década de 1950 cuando se levantaron las vías férreas del ferrocarril del Llano del Maipo dando continuidad a la ciudad hacia el oriente y siendo reemplazado este ferrocarril por un parque, para terminar con la demolición de una de las más bellas estaciones de ferrocarriles de la ciudad, como fue la estación Pirque o Providencia.

Otras acciones recientes y futuras buscan aprovechar los terrenos en desuso asociados al ferrocarril con el fin de reconvertirlos en sus usos, olvidando nuestra historia industrial, para así poder anexarlos a la ciudad y con ello traspasar la falta de continuidad que provocaba este anillo dentro de una ciudad que ya lo ha superado.
Sin embargo creemos que, si bien no podemos negarnos al progreso y desarrollo de las ciudades, la oportunidad que nos brindan tanto las estructuras fabriles como los terrenos asociados al ferrocarril y la industria no son despreciables y en la medida que los protejamos y reutilicemos estaremos ayudando a construir la memoria histórica de nuestras ciudades.

La puesta en valor de estas estructuras está aún lejos de ser adoptada como una costumbre por nuestra sociedad, lo que esperamos pueda revertirse en pos de la preservación de la identidad de nuestra ciudad para las futuras generaciones que vendrán. 